\title{
Review Article \\ Urine Telomerase for Diagnosis and Surveillance of Bladder Cancer
}

\author{
Angela Lamarca and Jorge Barriuso \\ Medical Oncology Department, Hospital Universitario La Paz, 28046 Madrid, Spain \\ Correspondence should be addressed to Jorge Barriuso, jorge.barriuso@idipaz.es \\ Received 21 March 2012; Revised 31 May 2012; Accepted 4 June 2012 \\ Academic Editor: Martin Schostak
}

Copyright ( $) 2012$ A. Lamarca and J. Barriuso. This is an open access article distributed under the Creative Commons Attribution License, which permits unrestricted use, distribution, and reproduction in any medium, provided the original work is properly cited.

\begin{abstract}
Bladder cancer has increased incidence during last decades. For those patients with nonmuscle involved tumors, noninvasive diagnosis test and surveillance methods must be designed to avoid current cystoscopies that nowadays are done regularly in a lot of patients. Novel urine biomarkers have been developed during last years. Telomerase is important in cancer biology, improving the division capacity of cancer cells. Even urinary telomerase could be a potentially useful urinary tumor marker; its use for diagnosis of asymptomatic and symptomatic patients or its impact during surveillance is still unknown. Moreover, there will need to be uniformity and standardization in the assays before it can become useful in clinical practice. It does not seem to exist a real difference between the most classical assays for the detection of urine telomerase (TRAP and hTERT). However, the new detection methods with modified TeloTAGGG telomerase or with gold nanoparticles must also be taken into consideration for the correct development of this diagnosis method. Maybe the target population would be the high-risk groups within screening programs. To date there is no enough evidence to use it alone and to eliminate cystoscopies from the diagnosis and surveillance of these patients. The combination with cytology or FISH is still preferred.
\end{abstract}

\section{Introduction}

Bladder cancer is a very frequent and aggressive malignant tumor. During 2011, it has been the fourth most frequent malignancy diagnosed in men and the ninth in women. Worldwide, the mortality of this tumor, three times higher in men than in women, was around 113000 deaths in men during the year 2011. The incidence increases significantly with the age, so the age-adjusted incidence rate for people under 65 years is 5,35 per 100000 habitants, and 119,76 per 100000 in people over 65 years [1].

The predominant histologic subtype found in the bladder is the transitional cell carcinoma, also known as urothelial carcinoma. The local invasion of the muscle layer in the bladder is the key prognostic factor in the approach of these patients because of the increased metastatic risk [2]. That is why the early diagnosis of the disease has a strong impact on the prognosis: those patients diagnosed earlier have a lower incidence of muscle layer affectation and use to have a better prognosis. In those patients without muscle invasion, the treatment is based on resection of the tumor by transurethral resection with adjuvant intravesical therapy (no consensus regarding the optimal drug and the optimal scheme) [3]. Second, the surgery approached for tumors with muscular involvement is radical cystectomy with bilateral pelvic lymphadenectomy. Adjuvant chemotherapy with 4 cycles of cisplatine-gemcitabine combinations is used when the tumor has reached the perivesical tissues (T3-T4) [3]. Finally, for the metastatic disease, the schedules commonly used are also gemcitabine combinations [3]. Last year, vinflunine was added to the list of drugs that have demonstrated usefulness in this setting [4-6].

\section{Urine Biomarkers: When to Use Them?}

The most common presenting symptom of patients with bladder cancer is asymptomatic microscopic hematuria or the painless macrohematuria. The percentage of symptomatic patients is difficult to say because most times the symptoms are intermittent and nondetected. Nevertheless, the early diagnosis methods based on urinary markers of bladder malignancies have been developed during the last year. There is hope to use them as early predictor of the 
disease, and also for the surveillance, so we could avoid the regular cystoscopy usually used for the control of the relapse of nonmuscle invasive bladder cancer $[7,8]$.

2.1. Initial Diagnosis. Urothelial cancer is usually suggested by microscopic or macroscopic hematuria and must be endoscopically excluded. However, a lot of benign lesions can produce this unspecific symptom, so even if the urine cytology could help, its low sensitivity makes a diagnostic cystoscopy required. The development of urine biomarkers could have a role in selecting those patients whom require the cystoscopy because of the higher probability of having a malignancy.

2.2. Surveillance. After treatment of nonmuscle invasive and superficial urothelial tumors, the high risk of recurrences makes a prolonged surveillance necessary. The gold standard test is cystoscopy and ureteroscopy. Nevertheless this semiinvasive technique that partially requires anaesthesia has got not only false negatives, but also side effects. So the design of supplementary harmless techniques as urine biomarkers could help in the surveillance of those low risk patients, in whom it could be used instead of the regular endoscopy.

\section{The Rationale of Using Urine Biomarkers and Current Status}

Urine is in continuous contact with the urothelium from the renal pelvis and calyxes ureters, bladder and urethra. Thus, looking for biomarkers of malignant disease in the urine makes sense.

The ideal diagnostic test should be noninvasive, inexpensive, easy to perform; the marker evaluated should be detected in early stage and grade tumors such as in situ urothelial carcinoma; the test should be highly accurate to reduce the rate of false positive and negative results.

Until now, the standard noninvasive urinary marker was urinary cytology. This technique was more sensible in high grade tumor than in low grade ones, with an overall sensitivity ranging $25-70 \%$ [28]. A lot of factors were involved in nonconsistent results, as the pathologist, the grade of the tumor, inflamative reactions of the urinary tract, test conditions, and so forth.

In the last years a great effort has been made in developing new noninvasive markers that are a hope to improve the results of the urine cytology. There are two basic methods for the study of these biomarkers: immunologic detection of soluble molecules in the urine and the analysis of the exfoliated cells from the urothelial epithelium (Table 1). With these methods we can identify proteins with increased expression in cancer cells, detect cellular antigens by immunohistochemistry or cytochemistry or identify genetic aberrations with fluorescent in situ hybridization (FISH) $[7,8]$.

Actually none of the urine biomarkers that have been studied has sufficient sensitivity to replace cystoscopy in the assessment of a suspected bladder cancer, which presents evidence to improve the results of the cystoscopy alone for the diagnosis or the surveillance of this malignancy.
TABLE 1: Different methods for studying urine biomarkers.

\begin{tabular}{ll}
\hline $\begin{array}{l}\text { Tests for molecular markers in } \\
\text { urine }\end{array}$ & $\begin{array}{l}\text { Tests for the analysis of } \\
\text { exfoliated cells }\end{array}$ \\
\hline Bladder tumor antigen & Automated cytology assays \\
Nuclear matrix protein 22 & Cytokeratin 20 \\
Nuclear matrix protein 52 & Telomerase \\
BCLA-4 nuclear matrix protein & Microsatellite DNA \\
BCLA-1 nuclear matrix protein & Chromosomal abnormalities \\
Survivin & Carcinoembryogenic antigen \\
Cytokeratin 8, 18, and 19 & Mucoproteins \\
Fibrin degradation products & $\begin{array}{l}\text { Nuclear morphology } \\
\text { abnormalities }\end{array}$ \\
Hyaluronic acid & DD23 \\
Hyaluronidase & Lewis X antigen \\
\hline
\end{tabular}

Additional clinical trials are necessary to determine the benefit of biomarkers and its cost-effectiveness [29, 30].

In Table 2 we summarize the most important urine biomarkers and their current stage of development [31].

\section{Telomerase in the Pathogenesis of Malignancies}

The role of the telomere and the telomerase in the pathogenesis of cancer has been widely studied [32-34].

Telomeres are repeated DNA sequences (TTAGGG) located in the $5^{\prime}$ ends of human cells chromosomes. This sequences loss up to 200 bases at the end of each DNA replication cycle, so they become shorter after each cellular division. The gradual loss of these repetitions plays an important role in cellular deaths, as when they disappear, the cell loses the division capacity and comes into apoptosis. Thus, telomere's shortening is related with aging and with cell's death: it is a way of controlling the number of times one cell can divide, so genetic aberrations (chromosome instability) can be avoided. The function of the telomeres is to prevent the loss of crucial genetic information.

The telomerase is a ribonuclease-protein complex that adds bases to the telomeres to $5^{\prime}$ end of the chromosome, avoiding its shortening and allowing cells to replicate indefinitely. This enzyme is working in selected cells in our organism as germ cells and other continuously proliferating cells (e.g., leukocytes). Cancer cells, have reactivated this function and that is the reason they are able to live longer than noncancer cells [35]. This overfunctioning telomerase gives to cancer cells a full range of biological capabilities needed to keep dividing, growing and to disseminate. In most advanced cancers, telomerase can be reactivated and not only maintain the length of the telomere but also directly regulate cancer-promoting pathways.

Telomerase is a reverse transcriptase that adds telomere repeats to chromosome ends. It is composed by different proteins as telomerase RNA component (TERC) and telomerase reverse transcriptase (TERT). Between them, H/ACA box is a sequence that defines a specific class of noncoding RNAs and that acts as guide for the modification of other 
TABLE 2: Current and emerging urinary biomarkers.

\begin{tabular}{|c|c|c|}
\hline Urine biomarker & Current status of development & Reference \\
\hline Bladder tumor antigen (BTA) & $\begin{array}{l}\text { Bladder tumor-associated antigen in urine can be detected. The human } \\
\text { complement factor H-related protein (hCFHrp) can be detected in the urine. } \\
\text { Quantitative (BTA-TRAK) and qualitative (BTA-stat) assays have been done. } \\
\text { Accepted for being used with cystoscopy. Sensitivity 50-90\%; specificity } 90 \% \text {; false } \\
\text { positive in urinary tract infections, calculi, benign prostatic hyperplasia and with } \\
\text { intravesical BCG or chemotherapy (specificity 50\%). }\end{array}$ & {$[9-11]$} \\
\hline Genetic aberrations & $\begin{array}{l}\text { (i) FISH: detection of genetic alterations in exfoliated cells in the urine (aneuploidy } \\
\text { of chromosomes } 3,7,17 \text {; loss of } 9 \mathrm{p} 21 \text { ). Cystoscopy is able to detect those patients } \\
\text { that are going to have an early relapse after all the treatment. } \\
\text { (ii) Loss of heterozygosity and microsatellite alterations in multiple chromosomes } \\
\text { can be detected by PCR. }\end{array}$ & {$[12-15]$} \\
\hline $\begin{array}{l}\text { Nuclear matrix proteins } \\
\text { (i) NMP22 } \\
\text { (ii) NMP52 } \\
\text { (iii) BCLA4 } \\
\text { (iv) BCLA1 }\end{array}$ & $\begin{array}{l}\text { Multiple nuclear matrix proteins are overexpressed in urothelial tumors and, after } \\
\text { the apoptosis of these cells, released into the urine. The most studied one is } \\
\text { NMP22, whose sensitivity is higher in high grade and in nonmuscle invasive } \\
\text { tumors. Its levels are associated with disease recurrence and progression and it can } \\
\text { be used together with the cystoscopy. }\end{array}$ & {$[16-19]$} \\
\hline $\begin{array}{l}\text { Cytokeratins } \\
\text { (i) CK8 } \\
\text { (ii) CK18 } \\
\text { (iii) CK19 } \\
\text { (iv) CK20 }\end{array}$ & $\begin{array}{l}\text { Cytokeratins (CKs) are proteins from the epithelial cellular cytoskeleton. Different } \\
\text { types of CK can be over-expressed in different epithelium, so we can find specific } \\
\text { CKs in urine in bladder cancer patients. They can be detected by ELISA or by } \\
\text { RT-PCR. Their usefulness is under additional studies. }\end{array}$ & {$[15,20,21]$} \\
\hline $\begin{array}{l}\text { Hyaluronic acid (HA) and } \\
\text { hyaluronidase (HAase) }\end{array}$ & $\begin{array}{l}\text { Both are measured by ELISA-like assays. HA regulates cell adhesion, so it can } \\
\text { promote tumor progression and distant metastases. HAase cuts HA into small } \\
\text { pieces promoting angiogenesis. These markers have promising results, thus having } \\
\text { apparent ability to detect low grade tumors better than other urine biomarkers. }\end{array}$ & {$[22,23]$} \\
\hline Survivin & $\begin{array}{l}\text { An inhibitor of apoptosis that can be detected in urine by RT-PCR techniques. New } \\
\text { studies are needed. }\end{array}$ & {$[24]$} \\
\hline Others & Fibrin degradation products, DD23, Lewis X antigen. & {$[25-27]$} \\
\hline
\end{tabular}

cellular RNAs. There have been described two different types of H/ACA boxes: H/ACA small nucleolar RNAs (snoRNAs) accumulated in the nucleolus and involved in modification of ribosomal RNAs; and H/ACA small Cajal body-specific RNA (scaRNAs), accumulated in Cajal bodies and involved in the modification of splicing RNAs. The H/ACA snoRNAs and scaRNAs direct this enzyme complex to their complementary RNAs (ribosomal RNAs and splicing RNAs, resp.). Dyskerin is another essential protein for telomeres' function, as it stabilizes all the complex formed until now and allows its function. The overexpression of any of these proteins can turn into an overfunction of telomerase [36].

But telomerase requires additional proteins for proper assembly and function in human cancer cells. TCAB1 is a WD40-repeat containing protein. It is associated with dyskerin and binds the CAB box in scaRNAs (not H/ACA snoRNAs or other small RNAs in Cajal bodies or nucleoli) into Cajal bodies of the cells promoting the telomerase function [37]. Depletion of TCAB1 or other protein of the complex disrupts telomerase localization to Cajal bodies and leads to progressive telomere shortening [33] (Figure 1).

\section{Telomerase as Cancer Marker: Urine Biomarker}

Telomerase is activated in $80-90 \%$ of human carcinomas [38]. The knowledge acquired by basic studies on telomere biology is being applied on the study of cancer and the development of telomerase-targeted therapies [39, 40].

Moreover the use of the telomerase inhibitors for cancer treatment, the telomerase quantification, has been also used, in this case, for diagnosis. Telomerase is activated in cancer cells, but not in normal somatic cells; therefore, its detection can be a diagnostic marker for cancer [38]. A recent example of this is a nonsmall lung cancer and osteosarcoma assay in which a telomerase repeat amplification protocol (known as TRAP-assay) was used. They observed that monitoring telomerase levels in blood cells could have potential applicability on diagnosis and disease surveillance [41-44].

5.1. Looking for the Best Diagnosis Method. After deciding to start studying telomerase as a cancer marker, multiple assays with known oncologic patients looking for the best method to detect malignancy were done. There have been designed two different ways of measuring the telomerase quantity in a tissue $[43,45,46]$.

(i) The first one, telomeric repeat amplification protocol (TRAP) assay, uses PCR amplification of a telomeric template with posterior analysis by ELISA or RT-PCR. This assay needs at least 50 copies of telomerase-expressing cells to have positive results, so the false negatives are something relatively frequent [47]. 


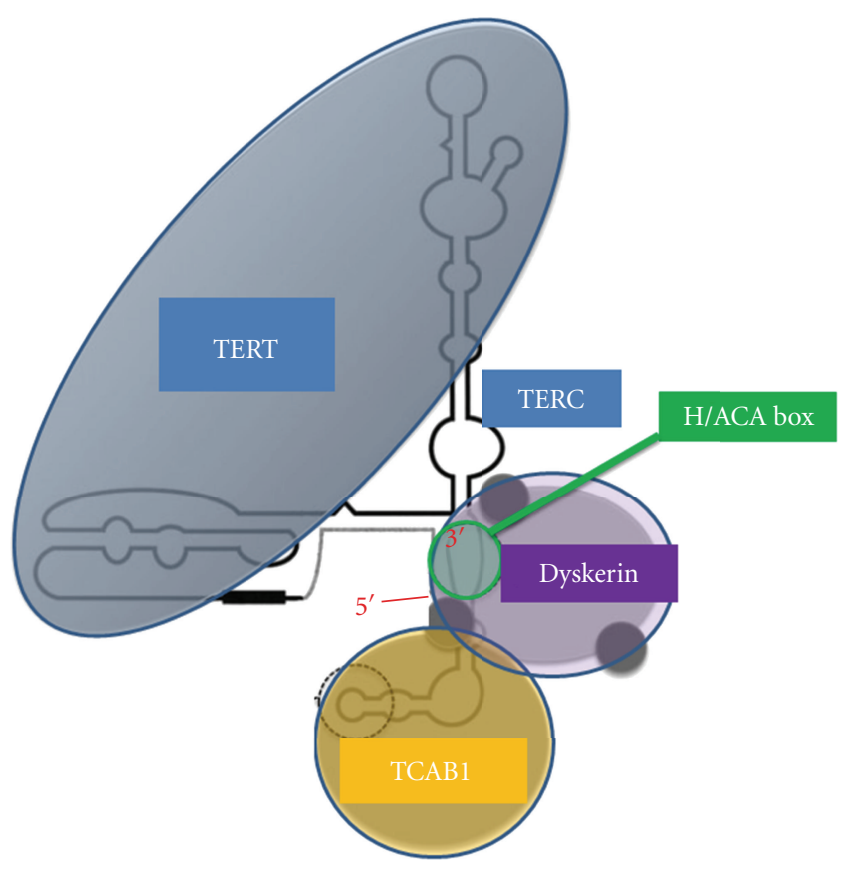

Figure 1: Telomerase complex.

(ii) The second one, human telomerase reverse transcriptase (hTERT) assay, measures the messenger RNA levels of the catalytic subunit of the telomerase by RTPCR [47].

Both assays have a sensibility between $70-100 \%$ and a specifity of $60-70 \%$ to detect cancer cells between the exfoliated cells of urine samples in symptomatic bladder cancer patients. The most used cut point is 50: so more than 50 copies of telomerase are interpreted as overexpression of telomerase [47]. Nevertheless, both can be affected by sample collection, processing, inflammation or infection with false positives results [48].

However, a lot of new studies are going on looking for the best diagnostic method; moreover, the combination of different urine biomarkers for urothelial cancer is being developed.

(i) It has been reported that human telomerase activity can be visualized by using primer-modified $\mathrm{Au}$ nanoparticles [49]. Even it seems to have better results; this new technique needs more investigation.

(ii) A Japanese group designed a modified method for the detection of telomerase in urine with a simple urine telomerase activity assay by a modification of the TeloTAGGG telomerase polymerase chain reaction (PCR) enzyme-linked immunosorbent assay kit. The sensibility and specifity obtained were $81 \%$ and $92 \%$, respectively, superior to other obtained by other groups [50].

(iii) The combination of cytology with either urine fibronectin, TRAP, or CK20 has demonstrated higher sensibility (S 98, 4\%) for diagnosis of malignancy in
132 patients with bladder cancer than cytology alone [51].

(iv) In a series of 123 patients with bladder cancer, the combination of hTERT and cytology was superior to the combination of cytology and the measure of another urine markers by RT-PCR with a sensibility of $71 \%$ and specifity of $86 \%$ [52].

5.2. Looking for the Validation and Its Impact in the Clinic. The expression of telomerase in cancer cells is related with their prolonged survival. This biomarker has been studied as serum parameter in multiple diseases [41-44, 53]. We are reviewing the most important assays supporting its utility as urinary biomarker of bladder cancer.

The usefulness of the techniques for the detection of telomerase in urooncologic patient urine has been demonstrated. As we have specified previously, they have got a sensibility between $70-100 \%$ and a specifity of $60-70 \%$ in known oncologic patients. The problem is bigger for the diagnosis of bladder cancer in patients with suspected malignancy; in this situation, few data are available yet.

The use of TRAP and hTERT seems to be similar in known oncologic urine samples. The problem is their development as diagnostic methods and the false positive index due to urinary symptoms, inflammation or infection is something to resolve. Even more, the lack of a strict relationship between hTERT protein expression and telomerase activity in validation trials has done telomerase activity in urine determined by TRAP which seemed to be a better method. Thus, TRAP has a great potential and more cost effectiveness when used, not for known oncologic patients urine malignant cellular detections, but for the diagnosis of malignancy in symptomatic patients and within high-risk subgroups $[54,55]$.

The sensibility and specificity of telomerase measure in urine for the diagnosis of urothelial/bladder cancer have been studied in a lot of different assays with different methods and results: overall the sensibility is between $60-87 \%$ and the specificity is around $65-90 \%[47,56,57]$. This results increases according to stage and grade: so the positive rates are $83.3 \%$ for superficial and $42.1 \%$ for invasive stages and $83.3 \%$ for grade $1,66.7 \%$ for grade 2 , and $40.0 \%$ for grade 3 tumors; thus, telomerase activity is correlated with lower grade and lower stage bladder carcinomas [58, 59]. Specific assays done in women have confirmed this data [60].

Finally, as it happens in known cancer patients, the combination between different urine biomarkers improves its results. In 289 patients with urinary symptoms, the combination of TRAP and cytology, TRAP and urine FISH and TRAP with urine FISH and cytology got sensibility and specificity of 0,78 and 0,$60 ; 0,65$ and 0,$93 ; 0,78$ and 0,78 , respectively, for cancer diagnosis [56].

5.3. The Actual Recommendation. Even the development of urine telomerase is quite new; the diagnostic methods have been widely studied. This is one of the advantages of using telomerase beyond other urinary biomarkers: the properly designed diagnostic tests. However, urine biomarkers have 
not been compared between them, so no conclusion can be drawn about which marker is the best one. The results of the assays we have summarized above of telomerase as urine biomarker of bladder cancer recommend its use in combination with other urinary biomarkers as FISH or cytology in high risk patients $[61,62]$. We have not got yet enough evidence to eliminate cystoscopies from the diagnosis and surveillance of these patients.

\section{Conclusions}

Even urinary telomerase could be a potentially useful urinary tumor marker, depending on sensitivity and specifity in predetermined patients. Its use for diagnosis in symptomatic patients or its impact during surveillance is still unknown. Moreover, there will need to be normalization and standardization of the assays before they can become useful in clinical practice. Maybe the target population in whom we could use it will be in high-risk groups screening programs or as diagnosis or for surveillance programs. Nowadays there is no enough evidence to use it alone, and the combination with cytology or FISH is preferred, having said that, there is no sufficient data to avoid periodical cystoscopy.

\section{References}

[1] A. Jemal, F. Bray, M. M. Center, J. Ferlay, E. Ward, and D. Forman, "Global cancer statistics," CA Cancer Journal for Clinicians, vol. 61, no. 2, pp. 69-90, 2011.

[2] D. Castellano, J. Carles, E. Esteban et al., "Recommendations for the optimal management of early and advanced urothelial carcinoma," Cancer Treatment Reviews, vol. 38, no. 5, pp. 431$441,2012$.

[3] J. Bellmunt, A. Orsola, T. Wiegel, M. Guix, M. De santis, and V. Kataja, "Bladder cancer: ESMO clinical practice guidelines for diagnosis, treatment and follow-up," Annals of Oncology, vol. 22, supplement 6, pp. vi45-vi49, 2011.

[4] H. von der Maase, "Pemetrexed in transitional cell carcinoma of the urothelium," Oncology, vol. 18, no. 13, supplement, pp. 48-50, 2004.

[5] H. Von der Maase, "Gemcitabine-containing regimens in bladder cancer: a new standard of care," Seminars in Oncology, vol. 28, no. 3, supplement 10, pp. 1-3, 2001.

[6] J. Bellmunt, C. Théodore, T. Demkov et al., "Phase III trial of vinflunine plus best supportive care compared with best supportive care alone after a platinum-containing regimen in patients with advanced transitional cell carcinoma of the urothelial tract," Journal of Clinical Oncology, vol. 27, no. 27, pp. 4454-4461, 2009.

[7] A. P. Mitra and R. J. Cote, "Molecular screening for bladder cancer: progress and potential," Nature Reviews Urology, vol. 7, no. 1, pp. 11-20, 2010.

[8] D. Tilki, M. Burger, G. Dalbagni et al., "Urine markers for detection and surveillance of non-muscle-invasive bladder cancer," European Urology, vol. 60, no. 3, pp. 484-492, 2011.

[9] Z. Z. Cheng, M. J. Corey, M. Pärepalo et al., "Complement factor $\mathrm{H}$ as a marker for detection of bladder cancer," Clinical Chemistry, vol. 51, no. 5, pp. 856-863, 2005.

[10] R. Gibanel, M. J. Ribal, X. Filella et al., "BTA TRAK urine test increases the efficacy of cytology in the diagnosis of lowgrade transitional cell carcinoma of the bladder," Anticancer Research, vol. 22, no. 2 B, pp. 1157-1160, 2002.
[11] M. P. Raitanen, "The role of BTA stat Test in follow-up of patients with bladder cancer: results from FinnBladder studies," World Journal of Urology, vol. 26, no. 1, pp. 45-50, 2008.

[12] S. Schwarz, M. Rechenmacher, T. Filbeck et al., "Value of multicolour fluorescence in situ hybridisation (UroVysion) in the differential diagnosis of flat urothelial lesions," Journal of Clinical Pathology, vol. 61, no. 3, pp. 272-277, 2008.

[13] M. F. Sarosdy, P. Schellhammer, G. Bokinsky et al., "Clinical evaluation of a multi-target fluorescent in situ hybridization assay for detection of bladder cancer," Journal of Urology, vol. 168, no. 5, pp. 1950-1954, 2002.

[14] A. P. Berger, W. Parson, A. Stenzl, H. Steiner, G. Bartsch, and H. Klocker, "Microsatellite alterations in human bladder cancer: detection of tumor cells in urine sediment and tumor tissue," European Urology, vol. 41, no. 5, pp. 532-539, 2002.

[15] V. B. Lokeshwar and M. G. Selzer, "Urinary bladder tumor markers," Urologic Oncology, vol. 24, no. 6, pp. 528-537, 2006.

[16] H. S. Choi, S. I. Lee, D. J. Kim, and T. Y. Jeong, "Usefulness of the NMP22BladderChek test for screening and follow-up of bladder cancer," Korean Journal of Urology, vol. 51, no. 2, pp. 88-93, 2010.

[17] S. F. Shariat, C. Savage, T. F. Chromecki et al., "Assessing the clinical benefit of nuclear matrix protein 22 in the surveillance of patients with nonmuscle-invasive bladder cancer and negative cytology," Cancer, vol. 117, no. 13, pp. 2892-2897, 2011.

[18] A. M. Attallah, H. A. Sakr, H. Ismail, E. S. K. Abdel-Hady, and I. El-Dosoky, "An office-based immunodiagnostic assay for detecting urinary nuclear matrix protein 52 in patients with bladder cancer," British Journal of Urology International, vol. 96, no. 3, pp. 334-339, 2005.

[19] R. H. Getzenberg, B. R. Konety, T. A. Oeler et al., "Bladder cancer-associated nuclear matrix proteins," Cancer Research, vol. 56, no. 7, pp. 1690-1694, 1996.

[20] M. Sánchez-Carbayo, E. Herrero, J. Megías, A. Mira, and F. Soria, "Comparative sensitivity of urinary cyfra 21-1, urinary bladder cancer antigen, tissue polypeptide antigen and NMP22 to detect bladder cancer," Journal of Urology, vol. 162, no. 6, pp. 1951-1956, 1999.

[21] D. Fatela-Cantillo, A. Fernández-Suárez, V. Menéndez, J. A. Galán, and X. Filella, "Low utility of CYFRA 21-1 serum levels for diagnosis and follow-up in bladder cancer patients," Journal of Clinical Laboratory Analysis, vol. 19, no. 4, pp. 167171, 2005.

[22] V. B. Lokeshwar, C. Öbek, H. T. Pham et al., "Urinary hyaluronic acid and hyaluronidase: markers for bladder cancer detection and evaluation of grade," Journal of Urology, vol. 163, no. 1, pp. 348-356, 2000.

[23] C. C. Passerotti, M. Srougi, A. C. Bomfim et al., "Testing for urinary hyaluronate improves detection and grading of transitional cell carcinoma," Urologic Oncology, vol. 29, no. 6, pp. 710-715, 2009.

[24] V. Margulis, Y. Lotan, and S. F. Shariat, "Survivin: a promising biomarker for detection and prognosis of bladder cancer," World Journal of Urology, vol. 26, no. 1, pp. 59-65, 2008.

[25] J. Tsihlias and H. B. Grossman, "The utility of fibrin/fibrinogen degradation products in superficial bladder cancer," Urologic Clinics of North America, vol. 27, no. 1, pp. 39-46, 2000.

[26] S. M. Gilbert, R. W. Veltri, A. Sawczuk et al., "Evaluation of DD23 as a marker for detection of recurrent transitional cell carcinoma of the bladder in patients with a history of bladder cancer," Urology, vol. 61, no. 3, pp. 539-543, 2003. 
[27] J. Sheinfeld, V. E. Reuter, M. R. Melamed et al., "Enhanced bladder cancer detection with the Lewis $\mathrm{X}$ antigen as a marker of neoplastic transformation," Journal of Urology, vol. 143, no. 2, pp. 285-288, 1990.

[28] G. Mowatt, S. Zhu, M. Kilonzo et al., "Systematic review of the clinical effectiveness and cost-effectiveness of photodynamic diagnosis and urine biomarkers (FISH, ImmunoCyt, NMP22) and cytology for the detection and follow-up of bladder cancer," Health Technology Assessment, vol. 14, no. 4, pp. 1-4, 2010.

[29] M. P. Herman, R. S. Svatek, Y. Lotan, P. I. Karakiewizc, and S. F. Shariat, "Urine-based biomarkers for the early detection and surveillance of non-muscle invasive bladder cancer," Minerva Urologica e Nefrologica, vol. 60, no. 4, pp. 217-235, 2008.

[30] A. Bennett, "Telomerase and other novel approaches to bladder cancer detection," Clinical Laboratory Science, vol. 21, no. 3, pp. 185-192, 2008.

[31] J. Parker and P. E. Spiess, "Current and emerging bladder cancer urinary biomarkers," TheScientificWorldJournal, vol. 11, pp. 1103-1112, 2011.

[32] S. A. Stewart and A. A. Bertuch, "The role of telomeres and telomerase in cancer research," Cancer Research, vol. 70, no. 19, pp. 7365-7371, 2010.

[33] S. E. Artandi and R. A. DePinho, "Telomeres and telomerase in cancer," Carcinogenesis, vol. 31, no. 1, Article ID bgp268, pp. 9-18, 2009.

[34] L. E. Donate and M. A. Blasco, "Telomeres in cancer and ageing," Philosophical Transactions of the Royal Society B, vol. 366, no. 1561, pp. 76-84, 2011.

[35] D. Hanahan and R. A. Weinberg, "Hallmarks of cancer: the next generation," Cell, vol. 144, no. 5, pp. 646-674, 2011.

[36] S. Brandt, "TERT over-expression affects the growth of myocardial tissue derived from mouse embryonic stem cells," Differentiation, vol. 79, no. 1, pp. 1-8, 2010.

[37] Y. Chen and Q. Kong, "Nuclear translocation of telomerase reverse transcriptase: a critical process in chemical induced hepatocellular carcinogenesis," Neoplasma, vol. 57, no. 3, pp. 222-227, 2010.

[38] C. H. Chen and R. J. Chen, "Prevalence of telomerase activity in human cancer," Journal of the Formosan Medical Association, vol. 110, no. 5, pp. 275-289, 2011.

[39] C.-C. Lee, K.-F. Huang, D.-M. Chang et al., "Design, synthesis and evaluation of telomerase inhibitory, hTERT repressing, and anti-proliferation activities of symmetrical 1,8-disubstituted amidoanthraquinones," European Journal of Medicinal Chemistry, vol. 50, pp. 102-112, 2012.

[40] D. D’Ambrosio, P. Reichenbach, E. Micheli et al., "Specific binding of telomeric G-quadruplexes by hydrosoluble perylene derivatives inhibits repeat addition processivity of human telomerase," Biochimie, vol. 94, no. 3, pp. 854-863, 2012.

[41] J. D. Henson, Y. Cao, L. I. Huschtscha et al., "DNA C-circles are specific and quantifiable markers of alternative- lengtheningof-telomeres activity," Nature Biotechnology, vol. 27, no. 12, pp. 1181-1185, 2009.

[42] Y. S. Lee, K. Tae, S. H. Lee et al., "Change of telomerase activity in peripheral whole blood of head and neck squamous cell carcinoma patients before and after surgery: a pilot study," Clinical and Translational Oncology, vol. 13, no. 10, pp. 747752, 2011.

[43] Y. Liu, B. Q. Wu, H. H. Zhong, M. L. Xu, and W. G. Fang, "Detection of telomerase activity in cultured cells and tumor tissue of lung carcinoma by modified telomeric repeat amplification protocol," Pathology International, vol. 60, no. 5, pp. 386-394, 2010.
[44] B. Özmen, C. I. Duvan, G. Gümüş, M. Sönmezer, M. Gungor, and F. Ortaç, "The role of telomerase activity in predicting early recurrence of epithelial ovarian cancer after first-line chemotherapy: a prospective clinical study," European Journal of Gynaecological Oncology, vol. 30, no. 3, pp. 303-308, 2009.

[45] H. Xin, "Telomeric repeat amplification protocol: measuring the activity of the telomerase," Methods in Molecular Biology, vol. 735, pp. 107-111, 2011.

[46] A. L. McCleary-Wheeler, L. E. Williams, P. R. Hess, and S. E. Suter, "Evaluation of an in vitro telomeric repeat amplification protocol assay to detect telomerase activity in canine urine," American Journal of Veterinary Research, vol. 71, no. 12, pp. 1468-1474, 2010.

[47] V. Casadio, S. Bravaccini, R. Gunelli et al., "Accuracy of urine telomerase activity to detect bladder cancer in symptomatic patients," International Journal of Biological Markers, vol. 24, no. 4, pp. 253-257, 2009.

[48] M. I. Morsi, A. I. Youssef, M. E. Hassouna, A. S. El-Sedafi, A. A. Ghazal, and E. R. Zaher, "Telomerase activity, cytokeratin 20 and cytokeratin 19 in urine cells of bladder cancer patients," Journal of the Egyptian National Cancer Institute, vol. 18, no. 1, pp. 82-92, 2006.

[49] J. Wang, L. Wu, J. Ren, and X. Qu, "Visualizing human telomerase activity with primer-modified Au nanoparticles," Small, vol. 8, no. 2, pp. 259-264, 2012.

[50] I. Iwabuchi, K. Mori, H. Yamamoto et al., "Significance of A simple assay of urine telomerase activity for the detection of bladder cancer," Acta Urologica Japonica, vol. 56, no. 10, pp. 551-557, 2010.

[51] S. Eissa, M. Swellam, A. Amin, M. E. Balbaa, G. A. Yacout, and T. M. El-Zayat, "The clinical relevance of urine-based markers for diagnosis of bladder cancer," Medical Oncology, vol. 28, no. 2, pp. 513-518, 2011.

[52] A. S. Brems-Eskildsen, K. Zieger, H. Toldbod et al., "Prediction and diagnosis of bladder cancer recurrence based on urinary content of hTERT, SENP1, PPP1CA, and MCM5 transcripts," BMC Cancer, vol. 10, article 646, 2010.

[53] L. V. Svinareva, A. I. Glukhov, O. V. Zimnik, I. I. Bykov, T. V. Khorobrykh, and V. I. Shvets, "Detection of telomerase activity in gastric cancer," Biomeditsinskaya Khimiya, vol. 56, no. 5, pp. 602-608, 2010.

[54] R. Silvestrini, S. Bravaccini, V. Casadio, D. Amadori, and D. Calistri, "The current role of telomerase in the diagnosis of bladder cancer," Indian Journal of Urology, vol. 25, no. 1, pp. 40-46, 2009.

[55] S. Eissa, M. Swellam, R. Ali-Labib, A. Mansour, O. ElMalt, and F. M. Tash, "Detection of telomerase in urine by 3 methods: evaluation of diagnostic accuracy for bladder cancer," Journal of Urology, vol. 178, no. 3, pp. 1068-1072, 2007.

[56] S. Bravaccini, V. Casadio, R. Gunelli et al., "Combining cytology, TRAP assay, and FISH analysis for the detection of bladder cancer in symptomatic patients," Annals of Oncology, vol. 22, no. 10, pp. 2294-2298, 2011.

[57] M. A. Sanchini, R. Gunelli, O. Nanni et al., "Relevance of urine telomerase in the diagnosis of bladder cancer," Journal of the American Medical Association, vol. 294, no. 16, pp. 2052-2056, 2005.

[58] A. Okumura, I. Mizuno, O. Nagakawa, and H. Fuse, "Telomerase activity is correlated with lower grade and lower stage bladder carcinomas," International Journal of Urology, vol. 11, no. 12, pp. 1082-1086, 2004. 
[59] A. Dettlaff-Pokora, M. Matuszewski, and B. Schlichtholz, "Telomerase activity in urine sediments as a tool for noninvasive detection of bladder cancer," Cancer Letters, vol. 222, no. 1, pp. 83-88, 2005.

[60] S. Bravaccini, M. A. Sanchini, A. M. Granato et al., "Urine telomerase activity for the detection of bladder cancer in females," Journal of Urology, vol. 178, no. 1, pp. 57-61, 2007.

[61] D. Calistri, A. Sanchini, D. Amadori, and R. Silvestrini, "Telomerase activity: a molecular marker for early diagnosis of bladder tumor," Recenti Progressi in Medicina, vol. 98, no. 2, pp. 74-78, 2007.

[62] J. L. Campos-Fernandes, F. Descotes, J. André, P. Perrln, M. Devonec, and A. Ruffion, "Value of urinary markers in the diagnosis and follow-up of urothelial bladder tumours," Progres en Urologie, vol. 17, no. 1, pp. 23-34, 2007. 


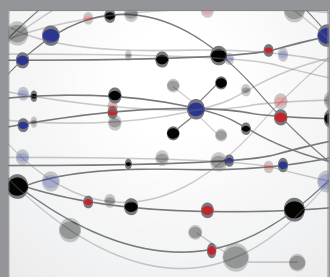

The Scientific World Journal
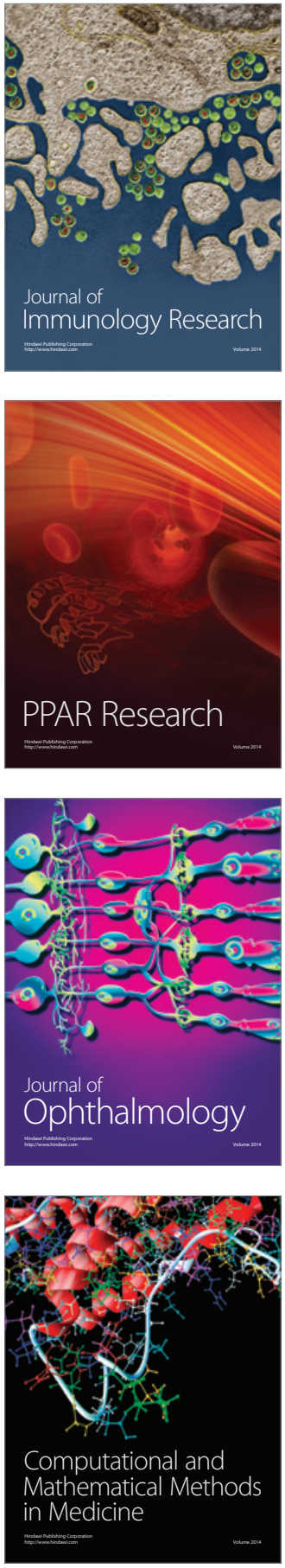

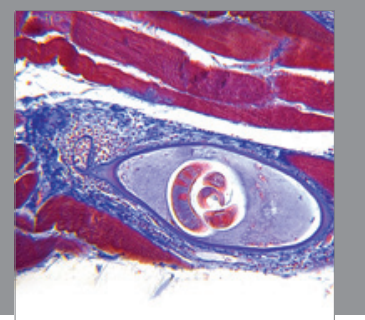

Gastroenterology

Research and Practice
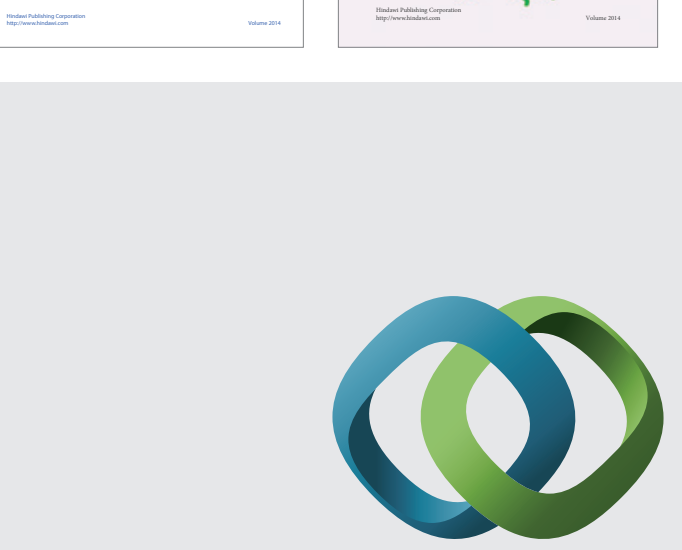

\section{Hindawi}

Submit your manuscripts at

http://www.hindawi.com
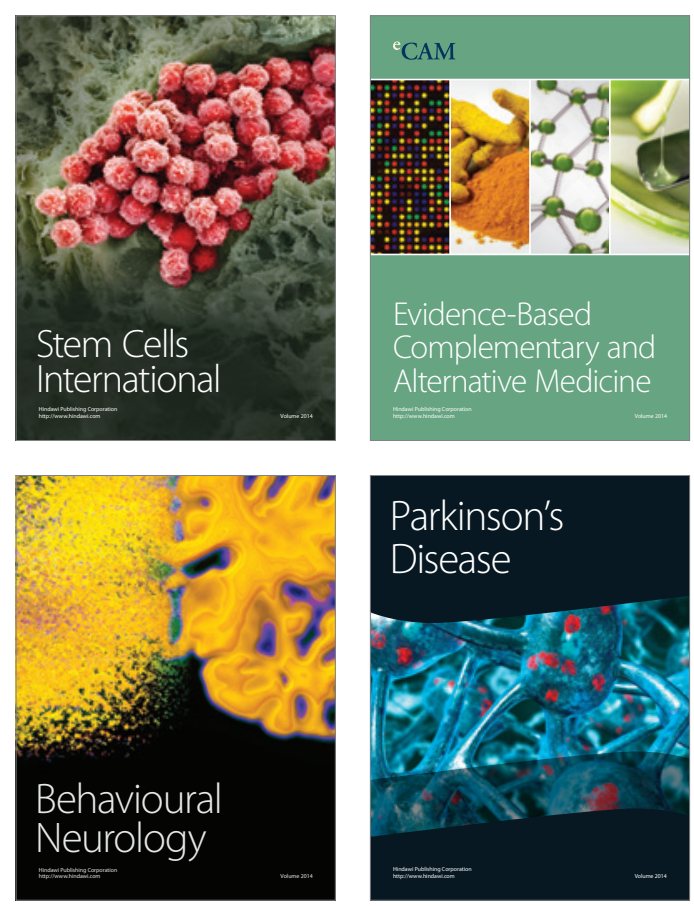

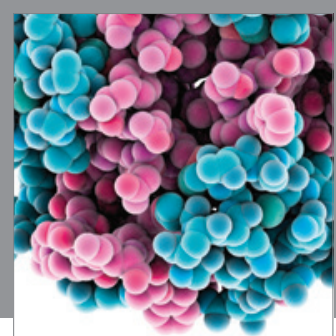

Journal of
Diabetes Research

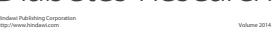

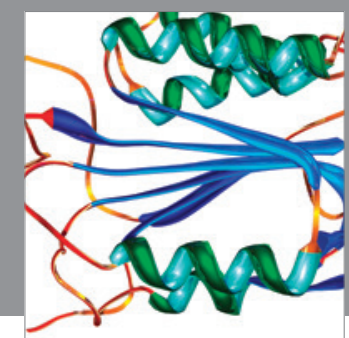

Disease Markers
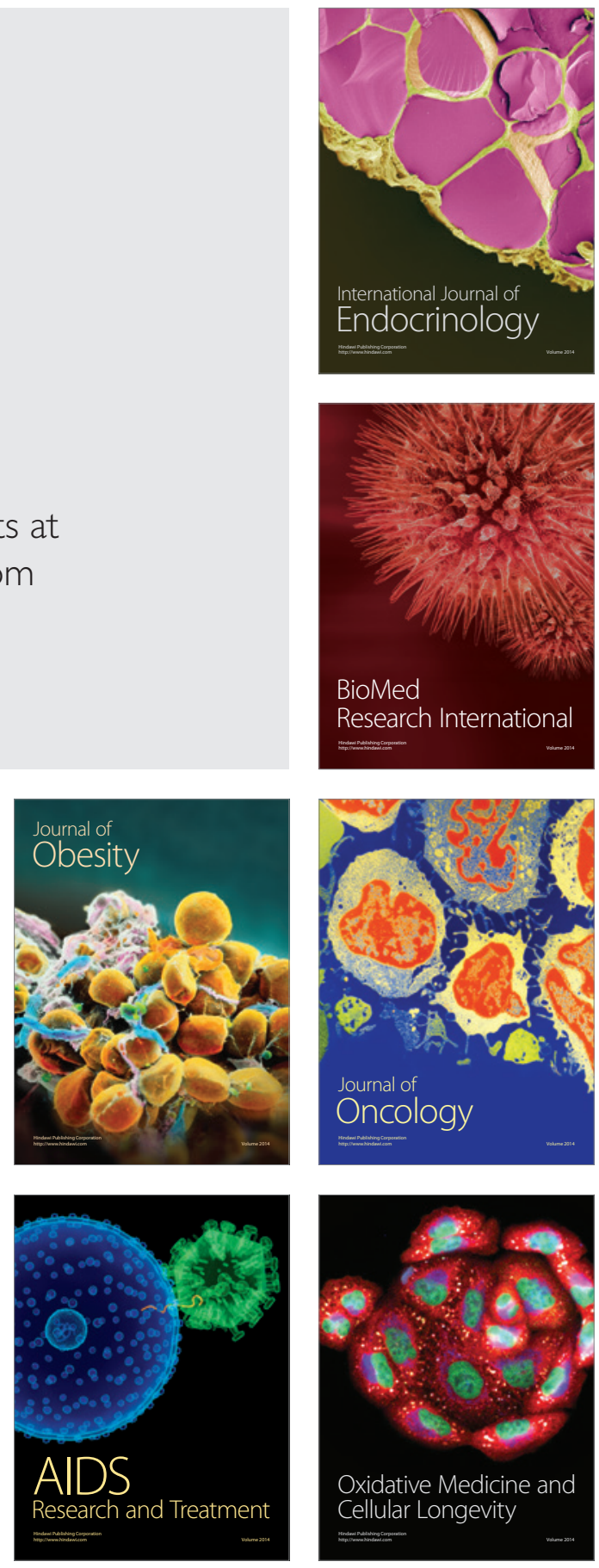